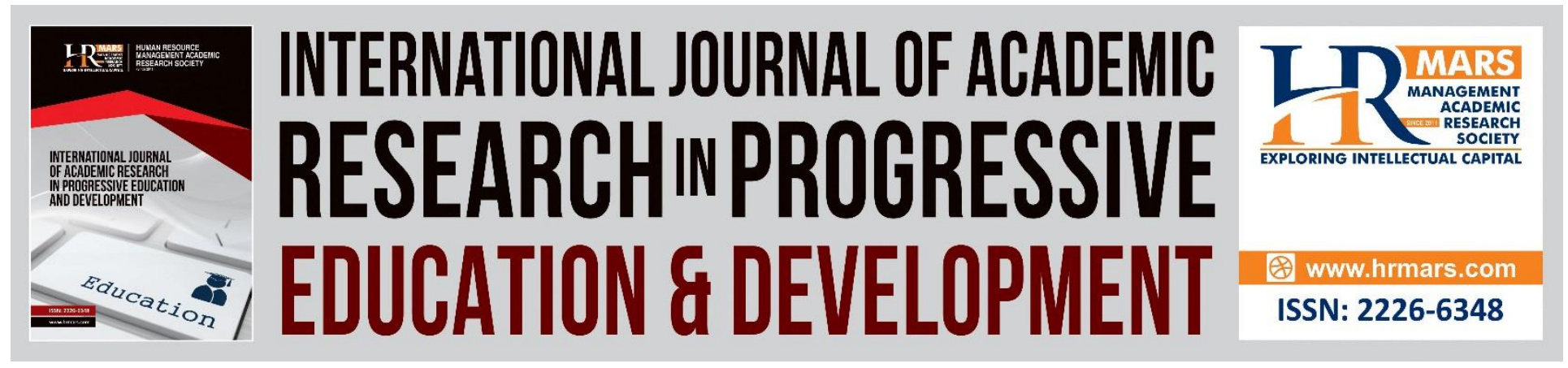

\title{
Hearts for Horses: A Fun Rehabilitation for Dyslexia
}

Kavenia Kunasegran, Vijayaletchumy Subramaniam

To Link this Article: http://dx.doi.org/10.6007/IJARPED/v9-i2/7964

DOI:10.6007/IJARPED/v9-i2/7964

Received: 11 April 2020, Revised: 20 May 2020, Accepted: 19 June 2020

Published Online: 27 July 2020

In-Text Citation: (Kunasegran, \& Subramaniam, 2020)

To Cite this Article: Kunasegran, K., \& Subramaniam, V. (2020). Hearts for Horses: A Fun Rehabilitation for Dyslexia. International Journal of Academic Research in Progressive Education \& Development. 9(2), 674-686.

Copyright: (C) 2020 The Author(s)

Published by Human Resource Management Academic Research Society (www.hrmars.com)

This article is published under the Creative Commons Attribution (CC BY 4.0) license. Anyone may reproduce, distribute, translate and create derivative works of this article (for both commercial and non-commercial purposes), subject to full attribution to the original publication and authors. The full terms of this license may be seen at: $\underline{\text { http://creativecommons.org/licences/by/4.0/legalcode }}$

Vol. 9(2) 2020, Pg. 674 - 686

http://hrmars.com/index.php/pages/detail/IJARPED JOURNAL HOMEPAGE

Full Terms \& Conditions of access and use can be found at http://hrmars.com/index.php/pages/detail/publication-ethics 


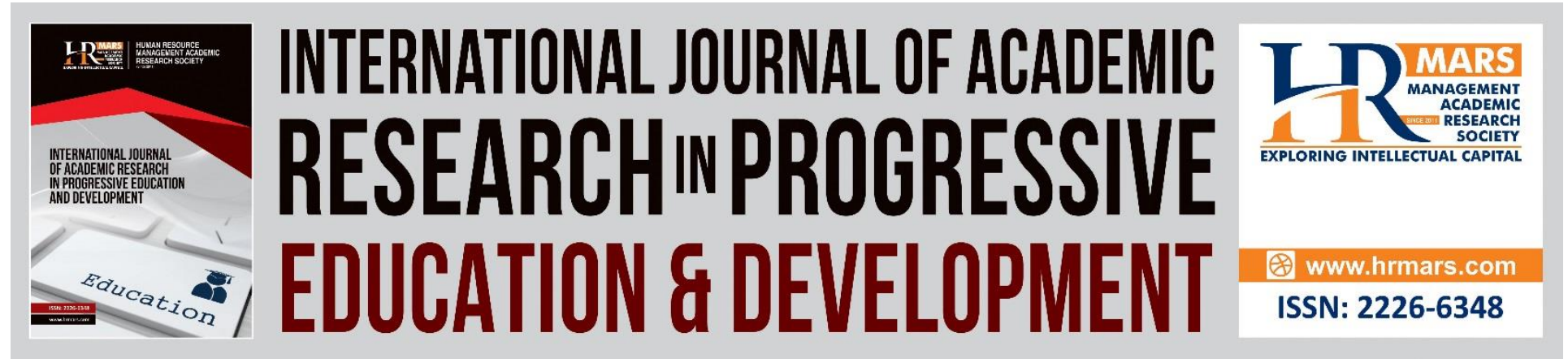

\title{
Hearts for Horses: A Fun Rehabilitation for Dyslexia
}

\author{
Kavenia Kunasegran, Vijayaletchumy Subramaniam, PhD
}

Faculty of Modern Languages and Communication, Universiti Putra Malaysia, Malaysia

\begin{abstract}
The purpose of this study was to investigate parents' perceptions and experiences of equine therapy for their dyslexic children. Twenty-four children were recruited from Malaysia Dyslexia Association in administering equine therapy. The research participants were parents of children with dyslexia. A sample size of twelve parents were therefore selected for the study. To complete this study, three modes of data collection was carried out, namely through observations, surveys and interviews. In this study, the researcher applied triangulation data by collecting three forms of data sources, namely questionnaires, audio and video recording and research field notes to increase validity and reliability of the research. Parents of the children in the treatment group gave feedback on their experience of equine therapy. Results from the parents demonstrated that their child has shown significant improvement in the following aspects, 1) physical \& motor skills, (2) psychological, (3) social, and (4) cognitive. The findings showed that this unique intervention has improved them directly in a fun and new rehabilitation. The majority of the parents felt that the equine therapy was effective in treatment of learning difficulties.

Keywords: Dyslexia, Equine Therapy, Animal-Assisted Therapy, Perception, Learning Disability.
\end{abstract}

\section{Introduction}

\section{Equine therapy}

The term 'hippotherapy' is a combination of two words 'hippo' which means horse and the word 'therapy' means treatment. Generally, 'hippotherapy' involves the use of a horse or animal as an aid in the process of treatment and recovery, 'animal-assisted therapy.' The term 'hippotherapy' was first introduced by Hippocrates in the 1960s. Historically, the ancient Greeks considered horseback riding not only as a means of transportation, but also as a means of maintaining health and well-being for the disabled (Hallberg, 2008). Hippocrates has emerged as the first to examine the benefits of horses in rehabilitation by referring to them as an 'universal exercise' (Hardy, 2011). According to the definition of Professional Association of Therapeutic Horsemanship International (2016), horse therapy is an equine-assisted activity with the aim of positively impacting the cognitive, physical, emotional and well-being of individuals with special needs. (Ward et.al, 2013). These benefits have led to the use of animals in two main types of interventions: Animal-Assisted Activities (AAA) and Animal-Assisted Therapy (AAT) (Lentini \& Knox 2009). The use of horses falls into both of these types of interventions, namely equine- 
assisted psychotherapy (EAP, a form of AAT), hippotherapy ( $H T$, a form of AAT), and therapeutic horseback riding (THR, a form of AAA). EAP uses horses to obtain psychotherapeutic outcomes (Lentini \& Knox 2009; Schultz, Remick-Barlow \& Robbins 2007), which include improved selfesteem and self-confidence (Kersten $\&$ Thomas, Schultz et al. 2007).

However, this horse therapy was not widely recognized until its use in Germany, Austria and Sweden in the 1980s. Prior to the recognition of horse therapy in European countries, traditional therapy for special need children was preferred domestically. The American Hippotherapy Association (AHA) established in 1992 has increased the awareness of physicians, psychiatrists, psychologists and the public about the benefits of equine therapy in the rehabilitation of various disorders experienced by special needs children, teenagers and adults. Recent studies conducted in Western countries have shown that horse therapy can improve physical, social, cognitive, psychological, learning and behavioural skills.

Studies have shown that animals can improve the quality of human life. This condition occurs when a person has a pet or is in contact with another animal for the purpose of treatment or recovery, namely animal-assisted therapy. This horse therapy is used to achieve the goals set by psychiatrists or psychologists before therapy begins. Horse therapy is unique since animals are sensitive and linked to the environment and mood (Ohrynowicz, 2007). To date, horse therapy is practiced in 48 countries with more than 650 horse therapy centres in the united states alone (Ohrynowicz, 2007). Today, more evidence of the benefits of horse therapy exists, but thorough studies are needed to expand this area of expertise.

Researchers explain that horse therapy occurs when psychologists use animal movements, especially horses, in an effort to improve one's function based on the psychologist's assessment and goals to be achieved. According to Kim \& Lee (2014), the concept of 'dynamic systems' has become a staple of horses in line with the achievement of modern therapeutic goals. This is because there are similarities between humans and horses in terms of 'walking'. This equation affects the motor sensory therapeutically.

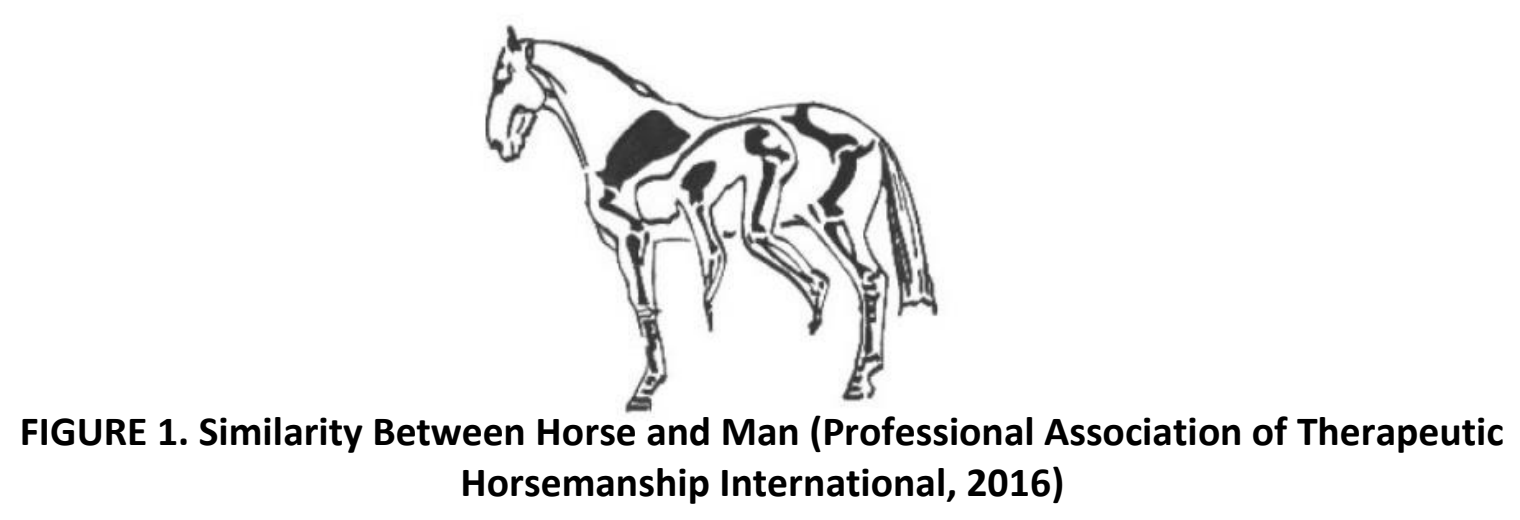

\section{Dyslexia}

Dyslexia is a specific learning disorder that affects up to $10 \%$ of school children. (Bull, 2007). The term 'dyslexia' originates from the combination of the Greek words ' $d y s^{\prime}$ ' which means 'difficulty' and 'lexis' which means 'language'. Literally, dyslexia means "language disorders" (Ott, 
1997). This term is referred to as a disorder that involves difficulty in reading or interpreting letters, words and other symbols. The definition of dyslexia was first originated by the World Federation of Neurology (1968). Dyslexic children have conventional classroom experiences but face challenges to master the language skills such as reading, writing and spelling in line with their intellectual abilities like normal children.

Disruptions in the learning process include difficulty in recognizing letters, reading, writing, speaking, counting, distinguishing coordination, and more. In terms of speech, dyslexic students have problems in pronunciation and communication. Most of them also have low selfesteem. This is because their level of speaking ability in both the oral and written aspects is not in line with the students' normal language ability. Aspects of speech involve psychomotor, cognitive, emotional and self-confidence. The dyslexic group is characterized by problems with verbal and non-verbal communication, social integration and motor function deficits. According to Kuruvilla, Murdoch \& Goozee (2007), horse therapy has an impact on the sensory recovery of 'gross motor systems' which will directly affect one's articulation and speech.

\section{Supporting Research for Equine Therapy}

Previous studies have shown that horse therapy has the potential to change the lives of children with special needs. This unique intervention also provides awareness to parents who face problems with their children. It has been proven by a study conducted by Sulkowski (2015) on equine therapy. Parental feedback was collected as the primary data of this study and allowed the researcher to analyze the effectiveness of horse therapy in language acquisition by prioritizing parental support for dyslexic children. In this study, researchers also call for more studies of horse therapy to focus on the holistic balance of special needs children and not just their concepts and interventions involved.

In examining the effectiveness of horse therapy from the language and social aspects, a study conducted by Anderson \& Meints (2016) evaluated the impact of horse therapy activities on children's social and adolescent functioning. The results show an increase in sensory integration, focus and social motivation. These three aspects are also emphasized in the "earlyassisted learning" approach. Recent studies that have expanded this field have found that horse therapy encourages children to communicate more directly, as an alternative to language acquisition. The effectiveness of equine therapy in both language and social skills has also been demonstrated in the study of Ghorban, Sedigheh \& Marzieh (2013) aimed at looking at the effects of horse therapy on children's special social skills. The literature review found that the study sample only rode horses for 45 minutes a week for 4 weeks.

Furthermore, a study of the effectiveness of horse therapy as an effective remedy by Tulay \& Atasevan (2015) also reinforces the findings of the study obtained by Sulkowski (2015). Previous studies have found that the appropriate study period to find out the effectiveness of horse therapy is three months. This has been backed up by a study conducted by Anderson \& Meints (2016) that carried out a two-month study. Although this study involved two groups as a sample of the study consisting of children with different disorders, namely autism and cerebral palsy, the appropriate age to study the effectiveness of horse therapy was in the 3 to 12-year-old age range which is also the advised age for dyslexia (Amirin, 2019). Previous studies have highlighted various alternative therapies for effective rehabilitation. For example, studies by 
INTERNATIONAL JOURNAL OF ACADEMIC RESEARCH IN PROGRESSIVE EDUCATION AND

DEVELOPMENT

Vol. 9, No. 2, 2020, E-ISSN: $2226-6348 @ 2020$ HRMARS

Odendaal (2000); Anderson and Olson (2006); Esteves and Stokes (2008), Zasloff and Hart (1999) introduced "therapy dogs". In these studies, researchers have shown that the therapy offers physiological, emotional and social support for children.

\section{Methodology \\ Research Question}

What are parents' perceptions and experiences of equine therapy for their dyslexic children?

\section{Research Design}

An exploratory qualitative research design was chosen for this study. This research design was selected as it is suited to the aim of the study. Qualitative research is more detailed of the subject being studied (Creswell, 2014). In addition, this design also provides a more in-depth approach and a broader understanding of the research being conducted. A descriptive qualitative research enables the researcher to explore parents' perceptions of equine therapy and not to restrict their thoughts to a definite or following precedence.

\section{Participants}

Twenty-four children were recruited from Malaysia Dyslexia Association in administering equine therapy. It was ensured that the psychologists at the centre included children that were diagnosed with only dyslexia and not have other disorders or complications. This is to avoid tainting the validity of the study. The research participants were parents of children with dyslexia. A sample size of twelve parents were therefore selected for the study. Purposive sampling was employed, which was based on the intended outcomes for the research (Lunenburg \& Irby 2008). The participants had to meet the following criteria for inclusion in the study:

- A participant had to be a parent of a child who participated in equine therapy activity.

- The child had to be clinically diagnosed with dyslexia.

- Parents have to be present at all times with their children during the equine therapy activity.

\section{Place of Study}

The researcher conducted the study at the Malaysia Dyslexia Association (Bangi branch) and the Equine Centre, Universiti Putra Malaysia. The Bangi dyslexia center is one of sixteen other branches of Malaysia Dyslexia Association in the whole of Malaysia. The Bangi dyslexia center consists of fifty-seven students and nine dyslexic teachers.

\section{Intervention}

(1) 4 sessions of equine therapy; 2 hours a session

(2) horse riding

(3) horse galloping

(4) sensory activities 


\section{Data Collection}

To complete this study, three modes of data collection was carried out, namely through observations, surveys and interviews. Observation is a method of data collection conducted on the subject of the study (Creswell, 2014). Through this observation, the researcher is able to obtain a general picture. The results will then be analysed descriptively. In this study, the researcher and parents observed the dyslexic children in all four series of equine therapy conducted. This observation was also performed to compare the results before and after equine therapy. Interviews are categorized into three types, namely structured interviews, semi structured interviews and unstructured interviews (Chua, 2014). In this study, the researcher conducted an informal face-to-face interview with the teachers of the Malaysia Dyslexia Association and parents of said children. The interview was conducted at the study site in a relaxed atmosphere. This interview aims to identify the equine horse therapy can benefit the children. Interviews were conducted orally and responses were recorded by the researcher using electronic media. The questions asked in this interview are general in order to get a comprehensive overview. Thirdly, questionnaires were also given out to determine the effectiveness of equine therapy of dyslexic children. The questionnaire was completed by the parents who was able to identify problems in the areas of speech, reading, behaviour, social skills, psychomotor skills and more. The questionnaire was a closed-form questionnaire consisting of items adapted from the "Equine-Assisted Learning" approach, American Hippotherapy Association. The items contained in this survey is able to achieve the objectives and research question of this study. Prior to distributing the questionnaire to the parents, the researcher obtained feedback from dyslexic specialists, therapists and psychologists to meet the validity of the research instrument.

\section{Data Analysis}

The verbal recordings were used to transcribe the interviews, and the transcriptions were analysed. The subject analysis seeks and analyzes themes that appear more than once in the data set (Braun and Clarke, 2006). The themes identified in the research include:

Table 1: Themes identified

\begin{tabular}{|l|l|}
\hline (1) Physical \& motor skills & (3) Psychological \\
\hline (2) Cognitive & (4) Social \\
\hline
\end{tabular}

\section{Trustworthiness}

In this study, the researcher applied triangulation data by collecting three forms of data sources, namely questionnaires, audio and video recording and research field notes. Triangulation is a combination of various data sources, researchers, theories, and methodological techniques in a study. There are four forms of triangulation (Denzin, 1978), namely data triangulation, researcher triangulation, theory triangulation and methodological technique triangulation. In a qualitative study, the more data is extracted, the higher the accuracy of the facts and the stronger its validity. The researcher implied triangulation data this study to strengthen the validity and reliability of the study. As a measure of the validity of the content of 
the questionnaire, the researcher reached out to three relevant experts. The field experts reviewed the questionnaire submitted to ensure that the questions are appropriate and able to achieve the objectives of the study. The validity of the content of the questionnaire were obtained from:

- A dyslexia specialist: she has reviewed the content on social, motor, cognitive and language problems faced by dyslexic children.

- An equine certified therapist: she has reviewed the content in terms of the relevance of the items as measured by the activities undertaken in horse therapy intervention.

- Two psychologists: they have reviewed the psychological content in measuring items that will be evaluated amongst children with dyslexia.

\section{Findings and Discussion}

Four main themes emerged from the data: (1) physical \& motor skills, (2) psychological, (3) social, and (4) cognitive. Equine therapy has proven to bring multiple benefits and various advantages to the participating children-and not only in one area. Many parents reported equine therapy as an activity that has positive physical, psychological, cognitive and social impacts on their children and no parents reported any disadvantages of said activity on their children.

\section{Physical \& Motor Skills}

Generally, dyslexic children do not have major problems or show difficulty in posture or movement as dyslexia is and language-based disorder. However, if the child is also diagnosed clinically with other disorders such as cerebral palsy, autism or attention-deficit hyper disorder, the child may show difficulty in this area. Balance and coordination are two of the most important gross motor skills in a child's physical development. It allows children to participate in physical activities and improves their ability to perform every day. According to McGibbon (2009), the horse's walk is in straight lines and gentle curves. Gradually, this will show modifications to the movement of the child. Activities such as changing position on the horse to improve dynamic control and motor skills (eg, backward sit, supine to sit, trunk rotation, and side-sit). In this study, the researcher focuses on three aspects in physical and motor skills, namely coordination, balance and motor skills. According to Shurtleff (2009), the sensory motor in question is related to the neurobiological function, which is the basic function of the foundation of speech. This is supported by the research evidence of Moser and Thrall (2015) entitled Impact of Horse Therapy on Coordination. Speech involves phonetic and phonological processing of letters with sound. The findings show that horse therapy is capable of directly addressing the subject of neurobiological research, impacting the speech of the child. The equine therapy conducted has improved the physical aspects of the children as described below:

- Coordination and balance

In terms of coordination, Luth shows improvement in his left and right hand/leg coordination. Before administering equine therapy, my son showed much difficulty in coordination. After his equine therapy sessions, I notice his posture and body balance has improved drastically. (Faiz, parent of Luth, 6 years old). 
- Motor skills

She has better grip control after his equine therapy sessions. The exercises have strengthened her fingers and hand grip control and this has helped her so much at school. She has a better grip at using a pencil and her handwriting is more readable now. (Tusirin, parent of Aafiya, 6 years old)

Both parents have reported that equine therapy does wonders for their child in terms of coordination, balance and motor skills in the physical area. It is a huge motivation for them and the parents believe that the intervention should be continued for long-lasting advantages.

\section{Cognitive}

Dyslexics generally have distinctive reading, writing and speech problems. Dyslexia is a learning disorder that affects the literacy domain, that is co-associated with perceptual, cognitive and language skills (Overy, 2003). Additionally, the cerebellar theory of dyslexia that was established proved the cerebellum is involved not only from the motor skills aspects, but also from the acquisition of skills related to language (Fawcett et. al, 1995). In terms of speech, dyslexic children have trouble speaking and communicating with others. This will directly cause problems in the learning process as the speech aspect is a fundamental element of the learning process. Most dyslexic students also noticeably have low self-esteem and mild anxiety. Academic improvement can be seen if the child shows more confidence and self-esteem (Boyd, 2017). Compared to their peers, dyslexic children may be physically and socially unstable. This can result in poor self-image, and less acceptance from peers. The emotional immaturity of dyslexics may render them uncomfortable in social situations. (Orton, 2007). They may be unaware of the amount of personal distance required in social interactions, or insensitive to the body language of other people. Dyslexia often affects the workings of the oral language. Individuals impaired may have difficulties finding the right phrases, may stammer, or may hesitate before addressing direct questions. This puts them at a disadvantage as they enter adolescence, when language becomes more central to their relationships with peers.

- Focus span

He is more focused in what he does at the present before straying his attention to other things around him. From my observation during the therapy activity, he is very transfixed when he is on the horse and concentrates on riding or moving exercises. (Hazmin, parent of Mukhlis, 7 years old)

She is listening before speaking more now compared to before her equine therapy sessions. I am able to make her understand things as she is more focused when I am talking to her. (Shariman, parent of Aisyah, 7 years old)

- Academic Improvement

He uses new words that he has learnt during the therapy sessions and he is proud to teach others of the new things he has learnt. Mostly, I noticed an increase is his vocabulary of animals, environment, actions, feelings and so on. (Ahmad, parent of Meor, 8 years old) 


\section{Psychological}

Horses contribute to the overall emotional well-being of children and generally enables them to be more positive (Anderson and Olson 2006). "Therapy horses" also contribute to these children's self-confidence by providing 'friends' to them (Zasloff and Hart 1999). Not only that, children are more caring and responsive to adults after equine therapy sessions. (Limond et al.1997). It is a therapeutic intervention to help improve their cognitive and language abilities. This intervention encompasses the importance of the multisensory aspect for children. In this study, the researcher focuses on three aspects psychologically, namely confidence, focus span and positive attitude.

\section{- Confidence}

Initially, my child was very hesitant and scared to approach the horses and take part in the activity. As the sessions progressed, he showed more confidence in trying something new - even touching the horse occasionally. I felt he has been very comfortable and looked happy when riding the horse. (Faqhtee, parent of Qayl, 6 years old)

There is a lot of changes in terms of behaviour of my child after equine therapy because she is more confident about herself and willingly participates in the activity. She also always looks forward to the next and this has a very positive impact on her. (Abidin, parent of Imanina, 6 years old)

\section{- Positive attitude}

He is more positive towards a new environment, people, changes and so on. He shows confidence that he is okay with trying something new. (Johan, parent of Amirul, 8 years old)

\section{- Self-esteem}

She feels very proud when she is on the horse and she feels like it something special to her. I have observed how her mood and attitude changes when she waits for her turn with the horse. (Iman, parent of Eldina, 8 years old)

It gives them confidence and pride thinking they are able to control a big animal when sitting on a horse. Helping my child to feel better about himself and deal effectively with his feelings has proven to be not an easy task over the years. (Hazmin, parent of Mukhlis, 7 years old)

Before equine therapy, my child almost never speaks and is silent at most times. But recently, she likes to share her thoughts about the horse and her day after a session. (Tusirin, parent of Aafiya, 6 years old)

\section{- Motivation}

After every session, my child asks me every day when would his next session be. It motivates him every day as it gives him something to look forward to. (Alex, parent of Hayder, 10 years old) 
INTERNATIONAL JOURNAL OF ACADEMIC RESEARCH IN PROGRESSIVE EDUCATION AND

DEVELOPMENT

Vol. 9, No. 2, 2020, E-ISSN: $2226-6348 @ 2020$ HRMARS

- Anxiety

When getting on and riding the horse, he does not even look petrified or scared. Before exposing him to equine therapy, the sight of animals used to give him anxiety and he would be as far as he can from any animals. These therapy sessions have changed his social behaviour too. (Johan, parent of Amirul, 8 years old)

She is not scared to touch the horse's mane or head during the sessions. I was shocked to see this because she always had sensory problems and we did not know the best approach to help her. (Mohd, parent of Zara, 6 years old)

Five parents has described their perception and experience of equine therapy for their dyslexic children in terms of psychological aspects. It is understood that not only does equine therapy help in one specific area but it is very diversified. Parents have reported that their children have improved drastically in showing more confidence, establishing a better focus span, and having a better outlook in their daily lives. This new approach of modern rehabilitation proves that improvement can be made to help dyslexic children. It is vital that these special needs children receive the help needed as they suffer tremendously in psychological aspects. This duly affects their learning process and day to day lives. In light of self-esteem problems, four parents have reported that equine therapy has been very beneficial in helping their children's self-esteem more than what was expected at the initial stage. These special need children suffer from selfesteem as they face many challenges socially in their day to day lives. As for anxiety issues, although they did report equine therapy beneficiary to the children but the parents also commented that the therapy should continue as it takes a longer period of time to help curb anxiety issues in their children. Therefore, the parents of said children that participated in the therapy sessions were thrilled to experience a positive shift in their children's attitude after the sessions.

\section{Social}

A study conducted by Anderson \& Meints (2016) titled 'The Effects of Equine-Assisted Activities on the Social Functioning in Children and Adolescents with Disorders' evaluated the effect of 8-week horse therapy on the social function of children and adolescents. The study subjects ranged from 5 years to 16 years and the findings indicate that horse therapy intervention has improved the social functioning of the study subjects. A similar study was conducted by Bass.et al in 2009 that examined the effects of a 12-week horse therapy intervention. The results showed an increase in sensory integration, focus and social motivation. The study of Gabriels et al. (2015) expanded to focus on communication and social behaviour. Studies have also shown that horse therapy encourages children to use their hands more often when doing work and to build personal relationships with horses. This encourages children to communicate spontaneously and not just when asked to. (Dingman, 2008). In this study, the researcher focuses on three social aspects, namely ability to interact, articulation and reading and vocabulary.

- Ability to interact

Equine therapy has improved my child's ability to communicate better with people and he also shows improvement in his body gestures when communicating. He is less scared 
and opens up more to interact with family and new people in his surroundings. (Sanjay, parent of Darshigen, 9 years old)

She is more engaged when interacting now and is able to have eye contact during interaction. This is somewhat of a major advantage to her therapy sessions as it has changed her attitude and behaviour socially (Fadly, parent of Summayah, 6 years old)

\section{- Articulation and Reading}

I noticed that when my child tells me his therapy experience in excitement, he is much faster in wording and speech articulation. He loves to story me on his experience after he is done with his session and looks forward to sharing about it to anyone who listens to him. There is lesser speech delay and he is clearer when speaking. (Sanjay, parent of Darshigen, 9 years old)

Both her father and I have noticed her reading getting better as it is smoother and she pronounces her letters and words better now. It is also true that the therapy has positive cognitive impacts because her understanding and comprehension has elevated drastically. (Siti, parent of Khadijah, 6 years old)

An important advantage that the parents reported after administering equine therapy was the positive social impacts on their children. Five parents have shared that equine therapy has improved their childrens' lives as they can now interact, communicate, read and understand better. It was also emphasised that they enjoyed their experience of equine therapy.

\section{Conclusion}

The study has found equine therapy improves dyslexic children's lives and offers boundless benefits and advantages. Not only does equine therapy prove helpful psychologically, physically and emotionally - its' effects these children improve their communication and social skills tremendously. The findings show that horse therapy has the potential to change the lives of children and to provide the necessary awareness to parents who face challenges with their children. Also, responsible parents need to consider the dyslexia-induced emotional and interpersonal issues. Then they'd have to devise approaches that will help the dyslexic find satisfaction and achievement in education and personal relationships. Results from the parents demonstrated that their child has shown improvement in the following aspects, 1) physical \& motor skills, (2) cognitive, (3) psychological, and (4) social. Further research in this field is required to validate these findings. There proves to be uniformity across other studies done conducted by (Anderson \& Meints, 2016; Boyd, 2017; Gabriels et al., 2015) and many more.

\section{Acknowledgement}

The research was successfully supported by the Knowledge Transfer Grant Scheme, Universiti Putra Malaysia. Also, Malaysia Dyslexia Association and Sariah Amirin (President) contributed to the writing of this article. We also acknowledge the dedicated support of the participants of the study. 
INTERNATIONAL JOURNAL OF ACADEMIC RESEARCH IN PROGRESSIVE EDUCATION AND

DEVELOPMENT

Vol. 9, No. 2, 2020, E-ISSN: $2226-6348 @ 2020$ HRMARS

\section{Corresponding Author}

Vijayaletchumy Subramaniam, PhD

Faculty of Modern Languages and Communication

Universiti Putra Malaysia, Malaysia

Email: vletchumy@upm.edu.my/letchumy1617@gmail.com

\section{References}

Anderson, K. L., \& Olson, M. R. (2006). The value of a dog in a classroom of children with severe emotional disorders. Anthrozoos, 19(1), 35-49.

Anderson, S., Meints, K. (2016). The Effects of Equine-Assisted Activities on the Social Functioning in Children and Adolescents with Disorders. Journal of Autism Disorder, 46: 3344-3352.

Bass, M. M., Duchowny, C. A., \& Llabre, M. M. (2009). The effect of therapeutic horseback riding on social functioning in children with autism. Journal of Autism and Developmental Disorders, 39(9), 1261-1267:10.1007/s10803-009-0734-3.

Bull, L. (2007). Sunflower therapy for children with specific learning difficulties (dyslexia): A randomised controlled trial. Complementary Therapies in Clinical Practice, 13, 15-24.

Creswell, J. W. (2014). Educational Research: Planning, Conducting and Evaluating Quantitative and Qualitative Research. Pearson Publication.

Denckla, M. B. (1985). Motor coordination in children with dyslexia: Theoretical and clinical implications. In F.H. Duffy. Dyslexia: A neuroscientific approach. Boston: Little Brown.

Denckla, M. B., Rudel, R. G., Chapman, C., \& Krieger, J. (1985). Motor proficiency in dyslexic children with and without attentional disorders. Archives of Neurology, 42, 228-231.

Dingman, A. (2008). Hoof prints: Equine therapy for autistic children. Encounter: Education for Learning and Social Justice, 21(4), 11-13.

Fawcett, A. J., \& Nicolson, R. I. (1995). Persistent deficits in motor skill of children with dyslexia. Journal of Motor Behavior, 27, 235-240.

Franceschini, S., Gori, S., Ruffino, M. (2013). Action Video Games Make Dyslexic Children Read Better. Current Biology 23, 462-466.

Gee, N. R., Harris, S. L., \& Johnson, K. L. (2007). The role of therapy dogs in speed and accuracy to complete motor skills tasks for preschool children. Anthrozoos, 20(4), 375-386.

Ghorban, H., Sedigheh, R., \& Marzieh, G. (2013). Effectiveness of Therapeutic Horseback Riding on Social Skills of Children with Autism Spectrum Disorder in Shiraz, Iran. Journal of Education and Learning; Vol. 2, No. 3; 2013.

Hallberg, L. (2008). Walking the way of the horse. Exploring the power of the human-horse relationship. Bloomington, NY: iUniverse, Inc.

Hardy, J. C. (2011). Therapeutic riding and its effects on self-esteem (Education Masters). Fisher Digital Publications, Paper 68.

Limond, J., Bradshaw, J., \& Cormack, K. F. (1997). Behavior of children with learning disabilities interacting with a therapy dog. Anthrozoos, 10(2/3), 84-89.

Odendaal, J. S. J. (2000). Animal-assisted therapy-magic or medicine? Journal of Psychosomatic Research, 49(4), 275-280.

Orton, R. M. (2007). Social and Emotional Problems Related to Dyslexia. International Dyslexia Association Fact Sheet series. 
Overy, K. (2003). Dyslexia and Music: From Timing Deficits to Musical Intervention. Annals New York Academy of Sciences 999:497-505. Pg 497-503.

Ramus, F., Pidgeon, E., Frith, U. (2003). The relationship between motor control and phonology in dyslexic children. Journal of Child Psychology and Psychiatry 44:5 (2003), pp 712-722.

Snowling, M. (1990). Dyslexia: A Cognitive Development Perspective. Oxford: Blackwell.

Shaywitz, E. (1996). Dyslexia. London: Whurr.

Ward, S. C., Whalon, K., Rusnak, K., Wendell, K., \& Paschall, N. (2013). The association between therapeutic horseback riding and the social communication and sensory reactions of children with autism. Journal of Austism and Developmental Disorders, 43, 2190-2198.

Zasloff, R. L., \& Hart, L. A. (1999). Animals in elementary school education in California. Journal of Applied Animal Welfare Science, 2(4), 347. 